\title{
MODELO DE AVALIAÇÃO DE DESEMPENHO DE FOGÕES COM FOCO EM ERGONOMIA, UTILIZANDO O MÉTODO MCDA-C
}

\section{PERFORMANCE EVALUATION MODEL OF STOVES WITH ERGONOMIC FOCUS USING THE MCDA-C METHOD}

\author{
Diogo Vegini* E-mail: diogovegini@gmail.com \\ Felipe Tiago E. E. Back* E-mail: febacks@gmail.com \\ Leonardo Ensslin* E-mail: ensslin@deps.ufsc.br \\ Marcel V. Souza* E-mail: marcelviana@hotmail.com \\ Sandra R. Ensslin* E-mail: sensslin@gmail.com \\ Tiago P. S. O. Machado* E-mail: engtp@hotmail.com \\ *Universidade Federal de Santa Catarina, UFSC, Florianópolis, SC
}

\begin{abstract}
Resumo: Este artigo apresenta uma aplicação do método Multicritério de Apoio à Decisão Construtivista (MCDA-C) em uma situação de avaliação de desempenho de fogões. Utilizando técnicas de estruturação de problemas, o MCDA-C permitiu aos decisores deste contexto visualizar os critérios que devem ser tidos em conta num processo de seleção de fogões, auxiliando assim nas decisões de elaboração de projetos de desenvolvimento de produtos, bem como permitiu a mensuração ordinal e cardinal do desempenho dos fogões. A apresentação do estudo de caso deste trabalho irá utilizar como exemplo a área de ergonomia dos fogões.
\end{abstract}

Palavras-chave: Avaliação de desempenho. Ergonomia. Fogões. MCDA-C

Abstract: This paper presents an application of multi-criteria decision aid constructivist method (MCDA-C) in a situation of evaluating the performance of stoves. Using techniques for structuring problems, the MCDA-C allows decision makers view the criteria that must be taken into account in the selection of stoves, thereby aiding in the decision-making projects for product development, and to enable ordinal and cardinal measurement of stoves performance. The case study of presented in this paper will use as an example the area of stoves ergonomics.

Keywords: Performance evaluation. Ergonomics. Stoves. MCDA-C

\section{INTRODUÇÃO}

O processo de desenvolvimento de produtos auxilia a criação de produtos mais competitivos e, dessa forma, permite que as empresas estejam preparadas para as recentes mudanças no ambiente de negócios como a intensificação da concorrência, a redução do ciclo de vida dos produtos, o avanço das tecnologias e a busca constante por produtos de alta qualidade e baixo custo (FONSECA e 
ROZENFELD, 2012). As empresas buscam cada vez mais serem vistas como um processo de satisfação do cliente, não como um processo de produção de produtos. Os produtos são transitórios, mas os requisitos dos consumidores são contínuos (KOTLER, 2000). Logo o desempenho estratégico no desenvolvimento de produto está diretamente relacionado com as vantagens competitivas criadas pelas empresas frente aos seus concorrentes, como afirmam (WHEELWRIGHT e CLARK, 1992).

Estas vantagens são alcançadas à medida que as empresas identificam e traduzem as necessidades dos consumidores em produtos diversificados, onde a grande variedade de produtos é gerada através de uma combinação eficaz de inovações tecnológicas, mantendo-se a competitividade com relação ao custo (CLARK e FUJIMOTO, 1991). Assim verificam-se oportunidades de aperfeiçoamento em conseguir definir o que é realmente importante de forma explícita, através de um processo que gere conhecimento visando atender aos consumidores, ao invés de trabalhar com alternativas e, assim, entender quais serão os impactos de suas escolhas perante o seu objetivo geral.

Para resolver a grande complexidade que a customização criou no sistema de manufatura, é necessário utilizar uma ferramenta, para desmembrar a estrutura do produto em partes menores que permitam um melhor gerenciamento. Dessa forma pretende-se desenvolver um modelo de avaliação de desempenho de fogões para uma indústria de eletrodomésticos, capaz de identificar, organizar, mensurar e integrar os aspectos julgados pelos decisores como necessários e suficientes para avaliar um produto.

Esse artigo se divide em cinco seções, além dessa introdução. Na segunda seção se encontra a Fundamentação Teórica da presente pesquisa. $\mathrm{Na}$ terceira seção é apresentada a Metodologia de Pesquisa. Na quarta seção apresentam-se o Estudo de caso realizado para atingir o objetivo de pesquisa. A quinta seção compreende as Considerações Finais. Por fim, são apresentadas as referências bibliográficas utilizadas ao longo do texto. 


\section{FUNDAMENTAÇÃO TEÓRICA}

O método Multicritério de Apoio à Decisão construtivista selecionado para o presente, busca estruturar o contexto decisional tendo em vista desenvolver modelos nos quais os decisores possam fundamentar suas decisões, a partir do que eles acreditam ser o mais adequado (ROY, 1990).

Sua consolidação como instrumento científico ocorre somente a partir da década de 1990 com os trabalhos de (LANDRY, 1995; KEENEY, 1996; ROY, 1996; BANA E COSTA e ENSSLIN, 1999), dentre outros. Segundo (ROY e VANDERPOOTEN, 1996), o apoio à decisão parte do pressuposto de que os processos decisórios são complexos e tem em conta os limites da objetividade, tornando-se, assim, de fundamental importância a construção de modelos que contemplem a subjetividade dos atores envolvidos com a solução de problemas e/ou com $\mathrm{O}$ ato de decidir. Os processos decisórios, nesta visão, passam a ser personalizados (ENSSLIN e VIANNA, 2008)

O MCDA-C tem sua origem na Pesquisa Operacional (PO), a qual é uma ciência desenvolvida no período da Segunda Guerra Mundial para lidar avaliação de desempenho e contextos decisórios (ENSSLIN et al., 2010). Com o passar dos anos a PO evoluiu passando a utilizar-se também de conhecimentos de outros ramos da ciência para suas aplicações. Com isso, dividiu-se em dois grandes grupos: a PO Hard, que procura desenvolver modelos matemáticos e a busca de solução ótima para os problemas analisados, e a PO Soft, que está mais voltada em estudar a estruturação dos contextos decisórios, incluindo a inovação, propondo-se a servir como ferramenta de avaliação e apoio à decisão (ENSSLIN et al., 2010). Nesse sentido, o MCDA-C tem suas bases na PO Soft, pois tem como objetivo construir conhecimento sobre o contexto decisório e servir como ferramenta de avaliação e apoio à decisão.

Além disso, utiliza na sua aplicação o paradigma Construtivista para caracterizar a sua prática científica, cujo principal diferencial está no desenvolvimento de modelos personalizados que levam em conta fortemente os objetivos e valores dos decisores, possibilitando ao mesmo participar ativamente em 
todas as fases de desenvolvimento do modelo, legitimando-o constantemente (STOLT e ENSSLIN, 2009). (ROY, 1993; LANDRY, 1995) destacam a importância da visão construtivista no processo decisório, pois busca desenvolver o conhecimento através de um processo metodológico e científico. Conforme (ENSSLIN et al., 2001), cada decisor percebe e interpreta de forma diferente o contexto decisório. Percebe de forma diferente porque cada decisor tem seu próprio quadro de referência mental. Interpreta de forma diferenciada porque cada decisor tem diferentes valores, objetivos, crenças, relações sociais e de poder. Segundo (BRUNSWIK et al., 2001), cada indivíduo enxerga um determinado evento e faz julgamentos sobre o mesmo conforme o meio em que está inserido e, principalmente, embasado no seu conhecimento e em suas experiências. Em outras palavras, enxergará com as suas próprias lentes (ENSSLIN et al., 2010).

Com o intuito de expandir o conhecimento no decisor nos contextos com as características expostas, o método MCDA-C utiliza instrumentos de estruturação de informações capazes de permitir compreensão das conseqüências de decisões nos aspectos que o decisor julga relevantes. Dessa forma, o método MCDA-C é um instrumento recomendado para aquelas situações onde o decisor deseja melhorar seu entendimento da situação para poder atuar com consistência, fundamentação, transparência, domínio e propriedade para interagir com todos os atores envolvidos (LACERDA et al., 2010). O método MCDA-C reconhece os limites da objetividade como proposto por (BANA E COSTA, 1993; LANDRY, 1995; KEENEY, 1996; ROY, 1996; ENSSLIN et al., 2001; ROY, 2005) e, por meio do uso de instrumentos tais como entrevistas abertas, brainstorming, grafos, mapas de relações meio-fim, modelos de otimização, etc..., os operacionaliza.

E, assim, desenvolve no decisor um corpo de conhecimentos capaz de the permitir compreensão das consequências de suas decisões nos aspectos que ele julga importantes, sem impor os racionalismos da objetividade, tão úteis na física e na matemática, porém dissociados dos contextos decisórios específicos em que os decisores necessitam de apoio para explicitar e mensurar os valores e preferências que desejam ter em conta e não valores e preferências genéricos ou de outros casos similares, mesmo os bem sucedidos; desejam compreender e visualizar as 
consequências de suas decisões em seus objetivos; desejam estabelecer os desempenhos de referências em cada objetivo segundo sua percepção; desejam compreender a contribuição de cada critério nos objetivos estratégicos e, por fim, desejam valer-se da expansão do conhecimento propiciado pelo processo de apoio à decisão para identificar oportunidades de aperfeiçoamento.

\subsection{Ergonomia e Usabilidade}

A palavra Ergonomia deriva do grego Ergon [trabalho] e nomos [normas, regras, leis]. Esta é definida como uma disciplina científica relacionada ao entendimento das interações entre os seres humanos e outros elementos ou sistemas, e à aplicação de teorias, princípios, dados e métodos a projetos a fim de aperfeiçoar o bem estar humano e o desempenho global do sistema (POLETTO et al., 2008).

A usabilidade tem suas raízes nas áreas da ergonomia, psicologia, engenharias e desenho industrial. É uma filosofia que coloca o usuário no centro de todo o processo de desenvolvimento do produto, ou seja, os objetivos do produto, seu contexto de uso e todos os aspectos das tarefas que o produto irá suportar são derivados a partir da perspectiva do usuário (BETIOL, 2004).

De acordo com a norma (NBR 9241-11, 2002) usabilidade é uma "medida pela qual um produto pode ser utilizado por usuários específicos para atingir objetivos específicos com eficácia, eficiência e satisfação em um contexto específico"

\section{METODOLOGIA DE PESQUISA}

A seção de metodologia da pesquisa aborda os procedimentos para a construção do modelo multicritério. 


\subsection{Enquadramento Metodológico}

A seção de enquadramento metodológico visa tornar explícitos os procedimentos e técnicas utilizadas, além de facilitar a pesquisa tendo em conta um processo bem definido (BACK et al., 2012 No Prelo). Esta pesquisa pode ser caracterizada como aplicada de caráter exploratória, $\mathrm{O}$ que segundo (BORTOLLUZZI, 2009), objetiva proporcionar maior familiaridade com o problema, para torná-lo mais explícito. Além disso a pesquisa se caracteriza como qualiquantitativa. Os procedimentos para coleta de dados são de origem primária e secundária, pois foram obtidas por meio de entrevistas com os decisores e informações da empresa. Os dados foram utilizados no estudo de caso voltado para avaliação de desempenho de fogões, utilizando como instrumento de intervenção o método MCDA-C.

\subsection{Procedimentos para Construção do Modelo Multicritério}

A Figura 1 apresenta graficamente a construção do modelo de avaliação de desempenho que é realizada no método MCDA-C em forma sistêmica e sistemática em três fases que facilitam seu entendimento e aplicação: Fase de estruturação, Fase de avaliação e Fase de recomendações (BANA E COSTA e ENSSLIN, 1999). 
Figura 1 - Fases do MCDA-C

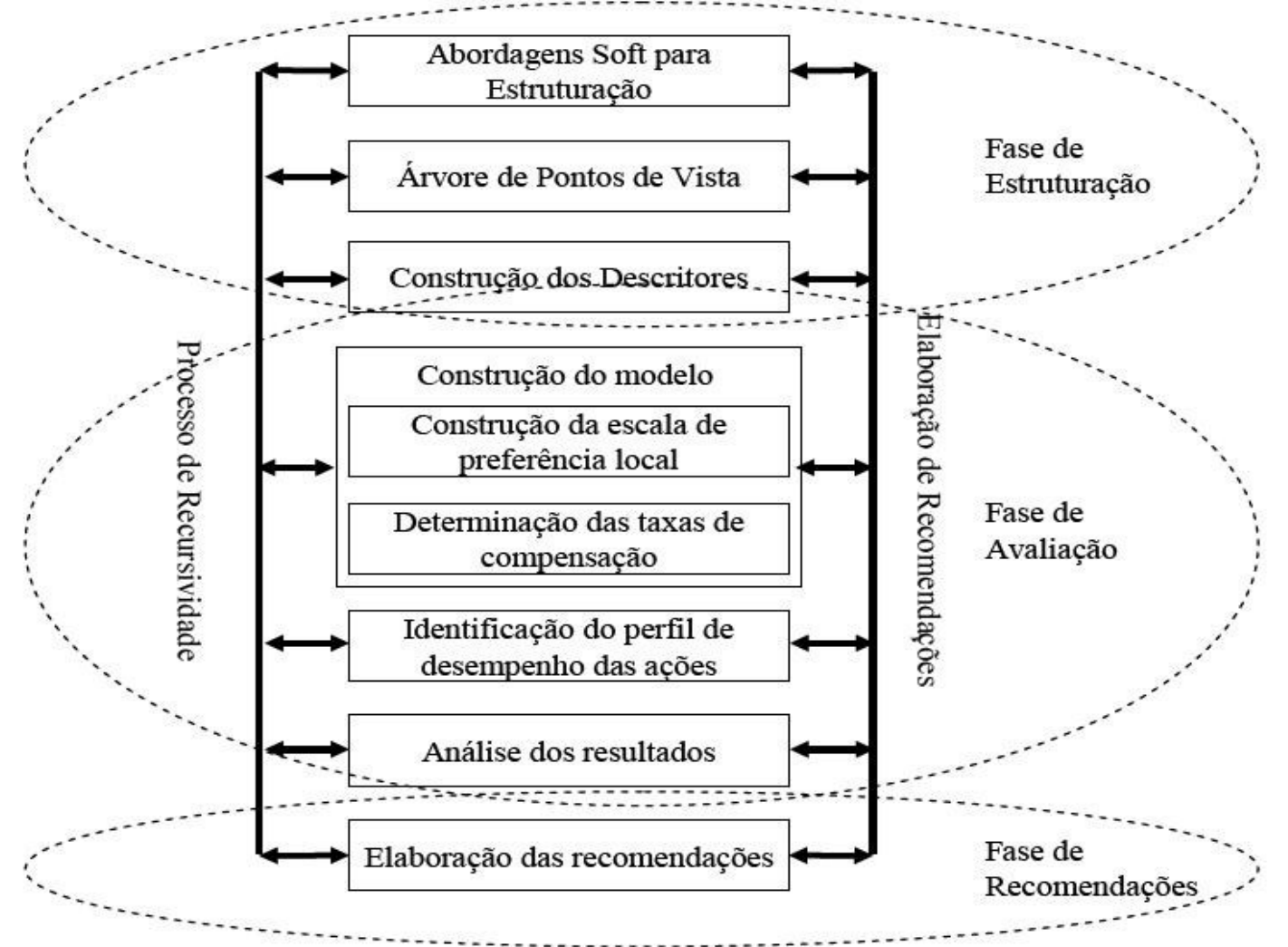

Fonte: Adaptado de (ENSSLIN et al., 2000)

\subsubsection{Estruturação}

A estruturação é a fase inicial do método e se constitui no fator mais crítico ao sucesso, pois visa o entendimento do problema e de todo o contexto onde o mesmo está inserido (ENSSLIN et al., 2005). Essa fase contribui ao identificar, organizar e mensurar ordinalmente as preocupações que o decisor considera suficientes e necessárias para a situação decisional. A estruturação se divide usualmente em quatro etapas: contextualização, identificação dos elementos primários de avaliação (EPAS), construção de mapas de relação meio-fim em paralelo com a construção das estruturas hierárquicas de objetivos e construção dos descritores. A etapa de contextualização aborda o ambiente onde o problema está inserido, quem são os atores envolvidos e quais os objetivos almejados (BORTOLUZZI et al., 2010)

A segunda etapa da estruturação é realizada por meio de entrevistas abertas onde o decisor é incentivado a mostrar suas preocupações, desejos e objetivos, denominados Elementos Primários de Avaliação (EPAs), que são os fatores 
essenciais do sistema de valores dos decisores. A seguir, é solicitado ao decisor para expandir o entendimento de cada EPA identificando a direção de preferência a ele subjacente assim como seu oposto psicológico associado às conseqüências que se deseja evitar. Cada EPA gera um ou mais conceitos orientados para a ação. Então, o decisor é incentivado a agrupar estes conceitos em clusters.

A terceira etapa consiste em demonstrar de uma forma explicativa as preocupações referentes ao problema construindo mapas de relação meio-fim utilizando os clusters gerados na segunda etapa. Nesta etapa é usual que novos conceitos emirjam (ENSSLIN et al., 2001). Cada cluster representa uma dimensão de avaliação compostas por candidatos a Pontos de Vista Fundamentais (PVF). Os conceitos geradores de cada candidato a PVF são utilizados para iniciar a construção dos mapas de relação meio-fim, seguindo o método proposto por (EDEN et al., 1983) para expandir o entendimento do contexto, segundo a percepção do decisor e identificar quais os aspectos julgados como relevantes. Este processo continua até que se tenha alcançado um grau de entendimento que permita estabelecer o conjunto de pontos de vistas que alinhem os objetivos estratégicos representados pelos PVFs do contexto com as propriedades operacionais. O mapa de relações meio-fim gerado é, então, transformado em uma Estrutura Hierárquica de Valor que representa os pontos de vista do mapa anterior em uma forma explicativa.

Finalizando a fase de estruturação são desenvolvidos os descritores, os quais podem ser definidos como escalas ordinais para descrever e mensurar 0 desempenho dos critérios de avaliação para cada PVF (ENSSLIN et al., 2001). Com o propósito de preparar estes indicadores de desempenho para serem utilizados em um modelo compensatório são estabelecidos dois níveis de referência denominados "Bom" e "Neutro" utilizando-se o processo proposto por (BANA E COSTA e ENSSLIN, 1999). Com os descritores é encerrado o processo de geração de conhecimento qualitativo. 


\subsubsection{Avaliação}

A segunda fase da construção do modelo multicritério é a fase de avaliação que consiste na incorporação de informações preferenciais dos decisores que permitam transformar as escalas ordinais em cardinais. A avaliação se divide em etapas de Construção das funções de valor e Identificação das taxas de substituição.

A função de valor explicita a diferença de atratividade entre os níveis e as Taxas de Substituição, a relação de compensação entre a atratividade dos intervalos de referência dos Pontos de Vista considerados (ENSSLIN et al., 2005). Para (ENSSLIN et al., 2001) as funções de valor são um instrumento para auxiliar os decisores a expressar, em forma numérica, suas preferências. Para todas as funções de valor foram identificados dois níveis de referência, chamados de nível "Bom" e nível "Neutro". O nível "Bom" corresponde à transição de um desempenho em nível de mercado para excelência. O nível "Neutro" corresponde à transição do nível comprometedor para o de mercado. O nível "Neutro" da escala foi fixado em 0 (zero) pontos e o nível "Bom" em 100 (cem) pontos, fazendo com que os níveis "Bom" e "Neutro" tenham uma representatividade equivalente em todos os critérios de avaliação do modelo (BORTOLUZZI et al., 2010; DIENSTMANN et al., No Prelo).

$\mathrm{Na}$ segunda etapa da fase de avaliação são identificadas as taxas de substituição, com o objetivo de permitir a avaliação global do modelo. Essas taxas podem ser calculadas com auxilio do software MACBETH X2 (Measuring Attractiveness by a Categorical Based Evaluation Technique) desenvolvido por (BANA E COSTA e VANSNICK, 2005) utilizando-se comparação par a par, permitindo com isso agregar as diversas dimensões de avaliação através de uma função de agregação aditiva na forma de uma soma ponderada.

Os modelos construídos pelo método MCDA-C permitem explicitar a avaliação em forma numérica e/ou gráfica. Isto facilita a identificação e compreensão da intensidade dos pontos fortes e fracos das alternativas avaliadas. 


\subsubsection{Recomendações}

A terceira fase do projeto é a fase de recomendações, que consiste em gerar ações para melhorar o desempenho em relação à situação atual. Essas ações são organizadas em estratégias para aperfeiçoamento do desempenho que melhor atenda aos objetivos do decisor. Nessa fase também é possível verificar a estabilidade das opções de escolha do decisor, realizando uma análise de sensibilidade no impacto das alternativas nas escalas, nas diferenças de atratividade das escalas cardinais, e nas taxas de compensação (ENSSLIN et al., 2001).

É possível verificar que a fase de recomendações evidencia um processo contínuo de expansão do entendimento do contexto ao buscar compreender as consequências das possíveis decisões nos critérios representativos das dimensões consideradas relevantes pelo decisor, bem como no contexto como um todo (ENSSLIN et al., 2001).

\section{ESTUDO DE CASO}

Tendo ciência das incertezas sobre a aceitação de determinados produtos pelos consumidores e, além disso, da complexidade presente nas atividades diárias dos departamentos de desenvolvimento e inovação de produtos, a aplicação do método MCDA-C neste estudo de caso faz-se necessária e é justificada pela capacidade de aprofundar os conhecimentos dos envolvidos sobre o assunto em questão: fogões. O MCDA-C também permite identificar quais são os pontos mais importantes para os decisores e, desta forma, orienta a atuação em pontos específicos e identifica o que a organização deverá fazer para alcançar níveis de excelência. O aprofundamento no estudo resultou em um completo modelo de avaliação de desempenho de fogões com dezenas de indicadores, que permitiram despertar para algumas oportunidades de inovação. No entanto, para melhor demonstrar a utilização do método empregado, representar-se-á apenas uma das áreas de preocupação do modelo: a usabilidade e dentro dela o foco será a ergonomia.

Revista Produção Online, Florianópolis, SC, v.12, n. 2, p. 423-454, abr./jun. 2012. 


\subsection{Fase de Estruturação}

Nesta fase será construído um modelo de avaliação de desempenho de fogões para dois funcionários de uma organização que produz produtos da linha branca, os quais trabalham no departamento de desenvolvimento de fogões. Portanto, ficam assim definidos como os decisores para a problemática apresentada e sob as lentes de quem a situação será percebida e interpretada, ou seja, a quem o modelo de apoio à decisão se destina: os Engenheiros de desenvolvimento de fogões e consumidores, identificados neste artigo como: "Decisor 1" e "Decisor 2".

Os decisores nesse estudo de caso tem as mesmas atribuições e participam da construção do modelo sempre juntos. Auxiliando na construção do modelo por meio de entrevistas em grupo os também engenheiros identificados neste artigo como: "Facilitador 1" e "Facilitador 2". Os demais atores envolvidos são os chamados intervenientes - que influenciam os decisores quanto a seus valores: os colegas de trabalho, a esposa do Decisor 1 e a Mãe do Decisor 2. Também existem aqueles que podem influenciar indiretamente, são os chamados agidos, neste caso, os demais familiares (pais, sogros, irmãos) e funcionários da empresa não diretamente ligados aos decisores. Vale ressaltar que os agidos não participam diretamente do processo proposto pelo MCDA-C. Estes apenas sofrem as consequências das escolhas dos decisores e podem em algum momento influenciar seus valores e preferências, porém sem grandes impactos. O Quadro 1 abaixo lista todos os atores envolvidos no contexto do problema.

Quadro 1- Atores

\begin{tabular}{|c|l|}
\hline Atores & \multicolumn{1}{c|}{ Descrição dos atores } \\
\hline \multirow{2}{*}{ Decisores } & Decisor 1 (Engenheiro de Produto e consumidor) \\
\cline { 2 - 2 } & Decisor 2 (Engenheiro de Produto e consumidor) \\
\hline \multirow{2}{*}{ Facilitadores } & Facilitador 1 (Engenheiro de Processos) \\
\cline { 2 - 2 } & Facilitador 2 (Engenheiro de Produto) \\
\hline \multirow{4}{*}{ Intervenientes } & Colegas de trabalho de ambos \\
\cline { 2 - 2 } & Esposa do Decisor 1 \\
\cline { 2 - 2 } & Mãe do Decisor 2 \\
\hline \multirow{2}{*}{ Agidos } & Demais familiares de ambos (pais, sogros, irmãos) \\
\cline { 2 - 2 } & Funcionários da empresa não diretamente ligados aos decisores \\
\hline
\end{tabular}

Fonte: Elaborado pelos autores (2010).

Revista Produção Online, Florianópolis, SC, v.12, n. 2, p. 423-454, abr./jun. 2012. 
Definiu-se como sendo o rótulo do problema: Modelo de avaliação de desempenho de fogões. Logo nas primeiras reuniões os facilitadores solicitaram que os decisores discorressem a respeito do problema e, por meio de suas declarações foram identificadas as características do contexto que impactam seus valores. Neste primeiro momento foram listados 83 EPAs, no Quadro 2 estão representados apenas 5 deles. Vale ressaltar que esses 83 EPAS não abordavam somente a área de usabilidade, mas sim outras áreas como estética e sustentabilidade.

Quadro 2- Alguns EPAs identificados

\begin{tabular}{|c|l|}
\hline EPA & \\
\hline 1 & Substituição lâmpada Descrição \\
\hline 2 & Facilidade de usar \\
\hline 3 & Enxergar \\
\hline 4 & Espaço \\
\hline 5 & Puxador que facilite a pega \\
\hline
\end{tabular}

Fonte: Elaborado pelos autores (2010).

Após esta etapa, os facilitadores se preocuparam em ampliar o entendimento dos decisores sobre cada EPA, identificando a característica desejável através da nomeação de seu oposto psicológico - mínimo grau aceitável para aquela característica. O Quadro 3 apresenta os conceitos formados a partir dos EPAs apresentados no Quadro 2. Para entendimento do grau de aceitabilidade das descrições, lê-se o símbolo “..." como "ao invés de” ou "é preferível a". O mesmo trabalho foi realizado com todos os demais EPAs, formando a mesma quantidade de conceitos.

Quadro 3- Alguns Conceitos

\begin{tabular}{|c|l|}
\hline Conceito & \multicolumn{1}{c|}{ Descrição } \\
\hline C1 & $\begin{array}{l}\text { Ter facilidade para trocar a lâmpada quando ela queimar ... Não conseguir trocar a } \\
\text { lâmpada e ter que chamar um técnico. }\end{array}$ \\
\hline C2 & $\begin{array}{l}\text { Ter facilidade para Montar/Desmontar os queimadores ... Encaixar os queimadores na } \\
\text { posição errada }\end{array}$ \\
\hline C3 & $\begin{array}{l}\text { Ter um forno com uma boa iluminação ... Ter que abrir a porta para verificar como está } \\
\text { o alimento. }\end{array}$ \\
\hline C4 & $\begin{array}{l}\text { Ter flexibilidade para movimentar panelas e formas ... Não poder virar formas no forno } \\
\text { ou ter dificuldade para movimentar as panelas na mesa. }\end{array}$ \\
\hline C5 & Ter um fogão que tenha puxador ergonômico ... Ter dificuldade para abrir o forno. \\
\hline
\end{tabular}

Fonte: Elaborado pelos autores (2010). 
Embasados nos conceitos criados, os decisores foram instigados a refletirem sobre um número de três a cinco grandes preocupações que explicassem o problema em questão. Um a um os conceitos foram classificados e, ao passo que algum conceito não se encaixasse em nenhuma das áreas uma nova área deveria ser criada. É importante e necessário ressaltar que cada área deve ser explicada não pelo nome que recebe, mas sim, pelos conceitos que nela estão contidos. Sendo assim, as primeiras áreas nomeadas foram: Estética, Sustentabilidade e Usabilidade. Ainda seguindo uma análise top down, área por área, os decisores refletiram sobre subáreas de preocupação, alocando os conceitos da mesma forma que o passo anterior. Desta forma, a Figura 2 revela as três macro áreas de preocupação e oito sub-áreas de preocupação e os seus respectivos conceitos.

Figura 2- Áreas e subáreas de preocupação e alocação dos conceitos

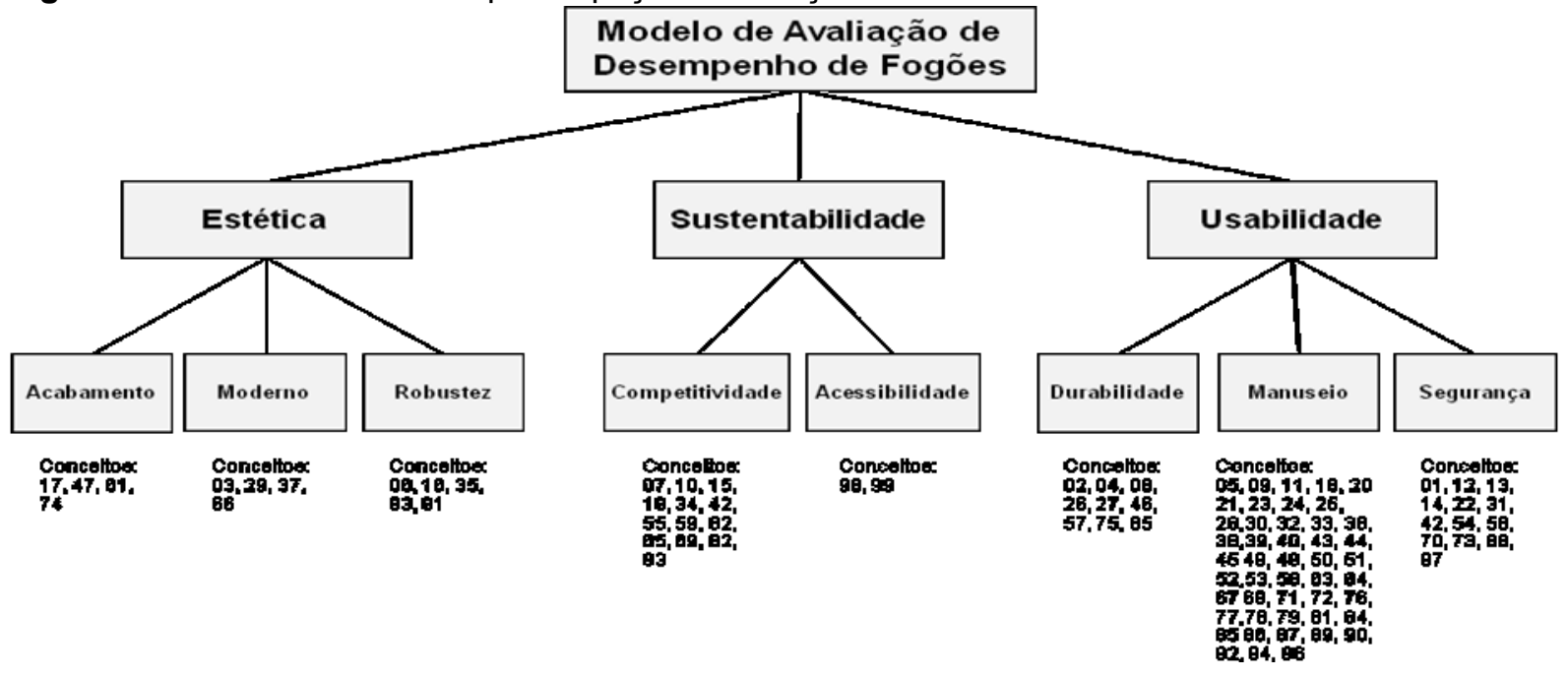

Fonte: Elaborado pelos autores (2010).

A partir de então, passou-se a analisar os conceitos no sentido contrário, bottom up, ampliando o entendimento sobre cada área por meio da construção dos mapas meio-fim (BANA E COSTA e ENSSLIN, 1999; ENSSLIN et al., 2000). No caso da subárea de preocupação "Manuseio", os conceitos nele contidos foram analisados pelos decisores através das seguintes reflexões: "Como eu posso obter esse conceito?" e "Por que esse conceito é importante?". Procurando sempre analisar a suficiência e a necessidade de cada um deles. Por meio deste mapa de raciocínio foram identificados 4 (quatro) novos conceitos não lembrados 
anteriormente pelos decisores. No mapa de raciocínio cada conceito-meio deve ser explicado pelos conceitos abaixo dele contidos, formando os chamados clusters grupo de conceitos que explicam uma determinada preocupação. Logo, ao analisar os clusters no sentido bottom up, 3 (três) subáreas dentro de Manuseio foram identificadas: "Fácil", "Efetivo" e "Versátil". A Figura 3 apresenta alguns dos subclusters identificados dentro da área de preocupação "Usabilidade", no cluster "Manuseio".

Figura 3 - Mapa Meios-fins para o cluster "Manuseio"

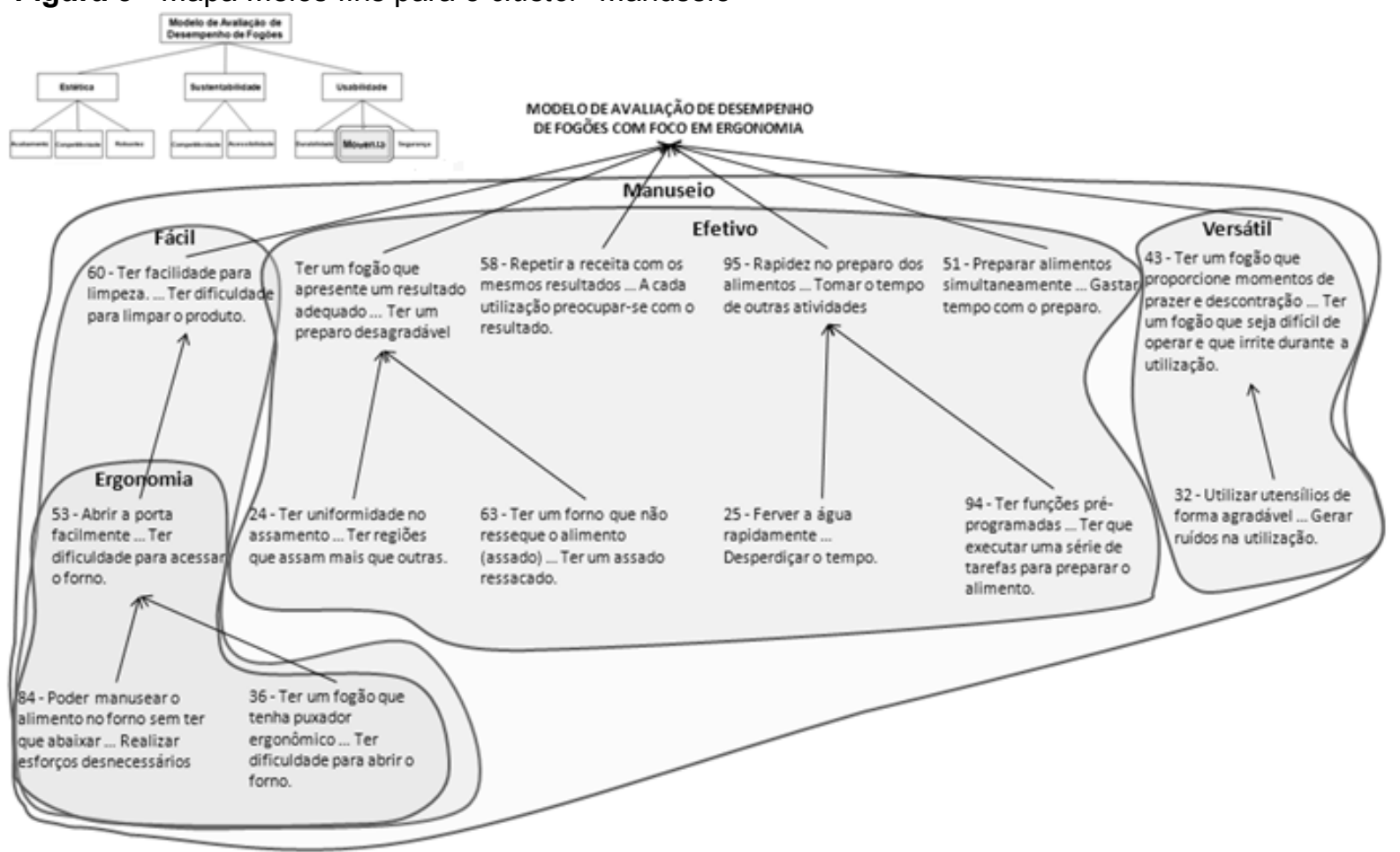

Fonte: Elaborado pelos autores (2010).

Para aumentar o nível de entendimento sobre o assunto a estrutura de relações de influência acima representada deve ser convertida em uma Estrutura Hierárquica de Valor. De acordo com (KEENEY, 1996; ENSSLIN et al., 2001; ROY, 2005) os clusters devem ser analisados quanto a serem: essenciais, controláveis, completos, mensuráveis, operacionais, isoláveis, não-redundantes, concisos e compreensíveis. Assim que os clusters atenderem a esses requisitos eles poderão ser convertidos para a Estrutura Hierárquica de Valor, se tornando um Ponto de Vista Fundamental (PVF), como representado na Figura 4 (LACERDA et al., 2011). 
Da mesma maneira foram analisados os subclusters que deram origem aos chamados Pontos de Vista Elementares (PVEs). Repetiu-se o procedimento até chegar a PVEs que representassem o contexto e que, além disso, permitissem a mensuração de maneira objetiva e não-ambígua. Sendo assim, para cada PVE construiu-se uma escala ordinal. Primeiramente, definiram-se os níveis âncoras "Bom" e "Neutro" e, após, foram agregados aos descritores níveis de excelência, aqueles que superam as expectativas dos decisores; níveis comprometedores, aqueles que ficam abaixo do nível neutro; e os níveis competitivos, ou seja, que ficam entre os níveis âncoras.

Figura 4- Estrutura Hierárquica de Valor

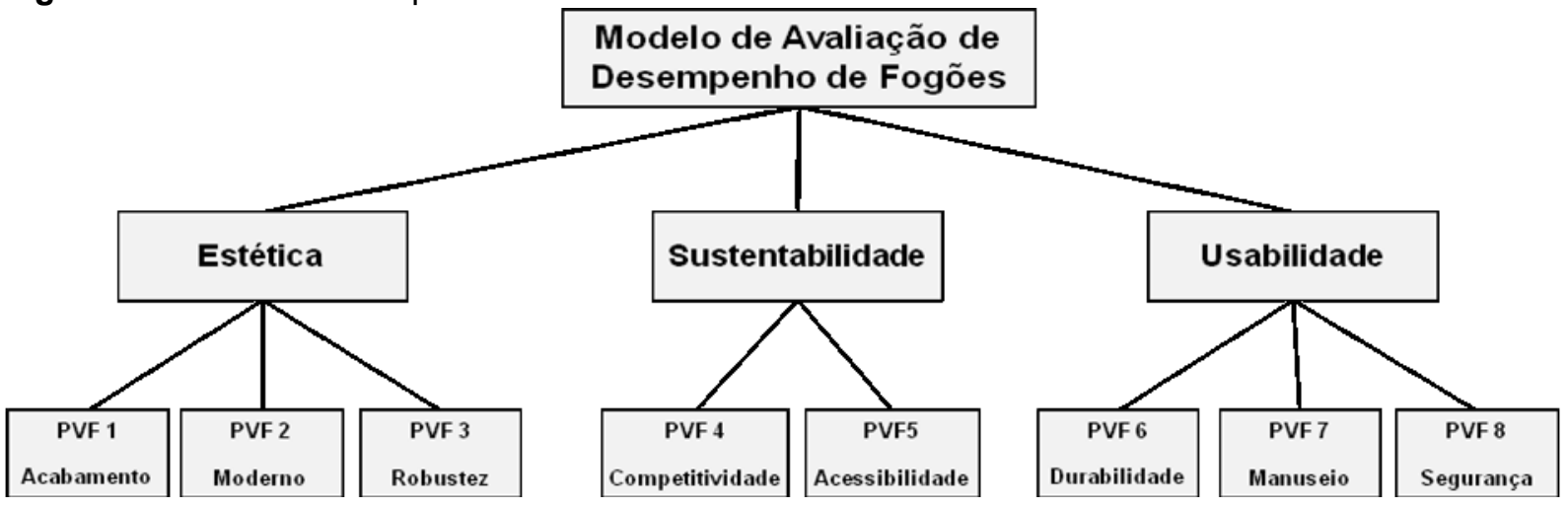

Fonte: Elaborado pelos autores (2010).

A Figura 5 demonstra a Árvore de Valor criada para o cluster "Ergonomia" e os descritores criados para cada PVE. No modelo completo, foram desenvolvidos 120 descritores. Vale ressaltar que durante a construção do conhecimento, novos conceitos foram criados, resultando neste número de descritores. 
Figura 5- Árvore hierárquica de valor, PVEs e escalas ordinais do PVF "Ergonomia"

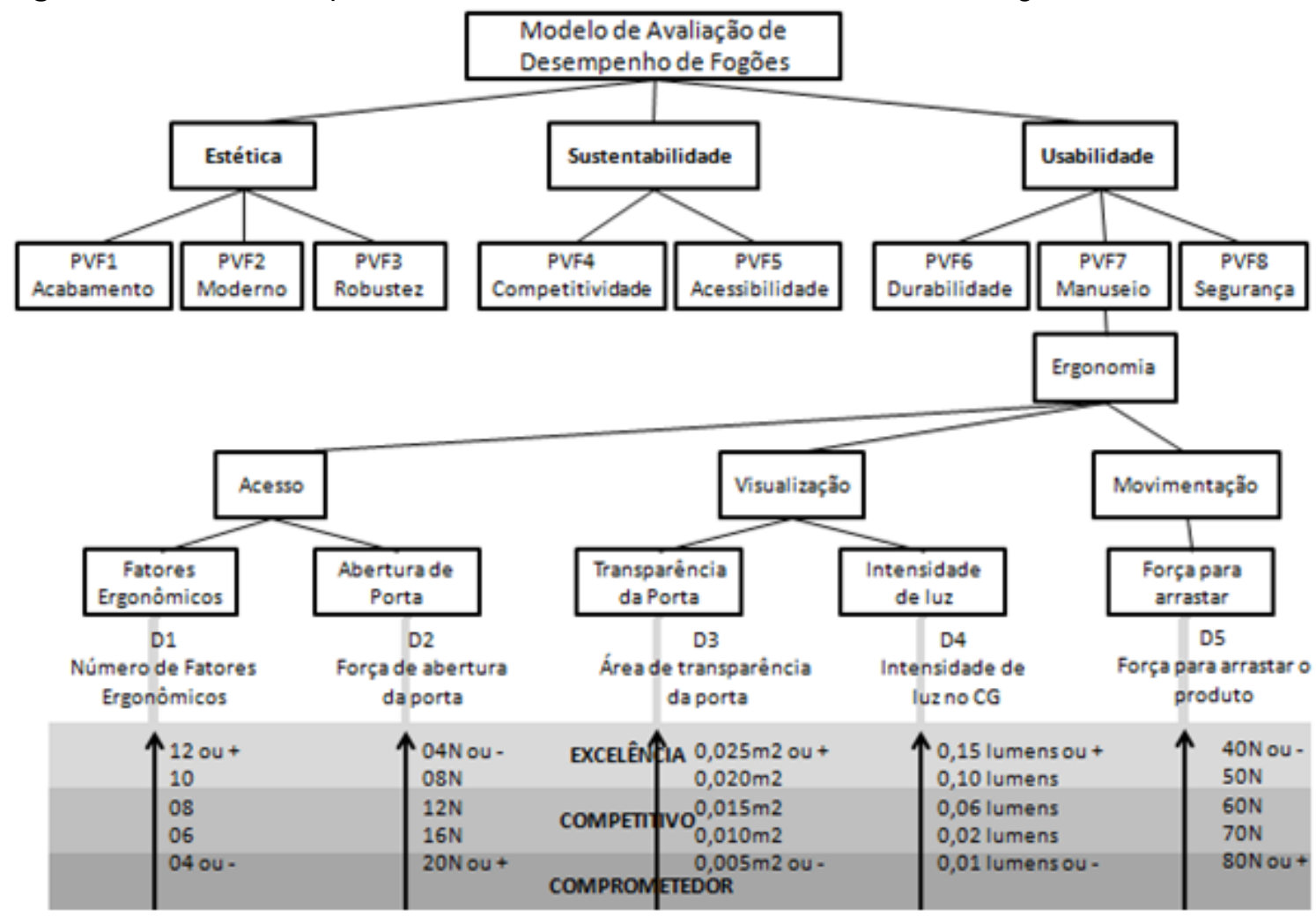

Fonte: Elaborado pelos autores (2010).

Finalizando esta etapa, conforme o método MCDA-C, conseguiu-se desenvolver o entendimento do contexto e expressá-lo por meio de escalas ordinais.

\subsection{Fase de Avaliação}

A segunda fase da construção do modelo multicritério é a fase de avaliação que consiste na incorporação de informações preferenciais dos decisores que permitam transformar as escalas ordinais em cardinais. A avaliação se divide em etapas de Construção das funções de valor e Identificação das taxas de substituição.

Devido aos descritores utilizarem escalas ordinais (qualitativas), nesta etapa do processo, não se deve realizar operações numéricas, para isso, deve-se realizar a transformação das escalas ordinais em escalas cardinais (quantitativas). O MCDAC recomenda a participação do decisor, para julgar as diferenças de atratividade 
entre os níveis de impacto dos descritores (ENSSLIN et al., 2001) e auxiliar na construção das funções de valor.

\subsubsection{Funções de Valor}

Para construção das Funções de Valor optou-se por utilizar o software MACBETH 2.3 (Measuring Attractiveness by Categorical Based Evaluation Technique). Primeiramente, são atribuídos os níveis "Bom" e "Neutro" determinados para cada descritor, que representam a pontuação 100 e 0 , respectivamente. 0 decisor deve então atribuir a diferença de atratividade para cada nível de um descritor, utilizando-se de uma escala semântica de sete níveis: Extrema, Muito Forte, Forte, Moderada, Fraca, Muito Fraca e Nula (BANA E COSTA e VANSNICK, 1997).

A Figura 6 apresenta o processo completo de transformação de um descritor (escala ordinal) em uma Função de Valor (escala cardinal): o descritor "Força de abertura da porta"; a Matriz de Julgamento; a Função de Valor, numérica e gráfica. Esse procedimento é realizado para todos os descritores. A Figura 7 apresenta as escalas cardinais construídas para o PVF "Ergonomia".

Figura 6- Transformação do Descritor "Força de abertura da porta" em Função de Valor por meio do MACBETH.
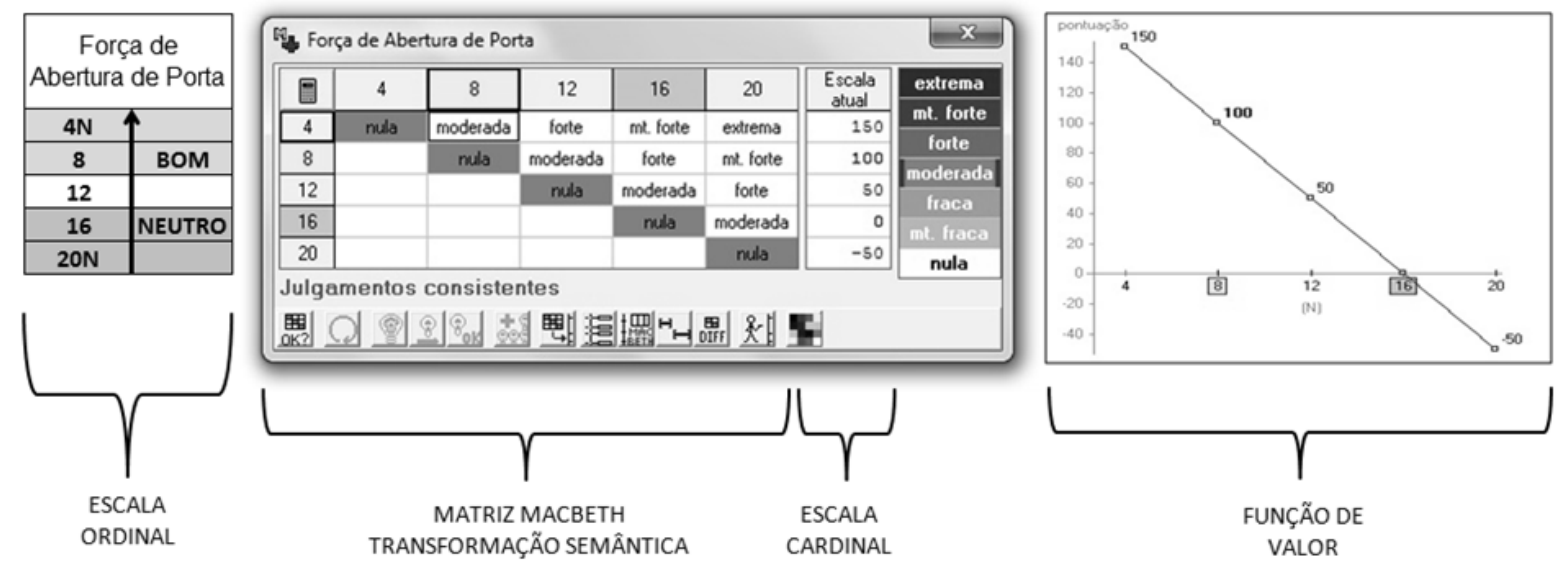

Fonte: Elaborado pelos autores (2010). 
Figura 7 - Escalas cardinais do PVF "Ergonomia"

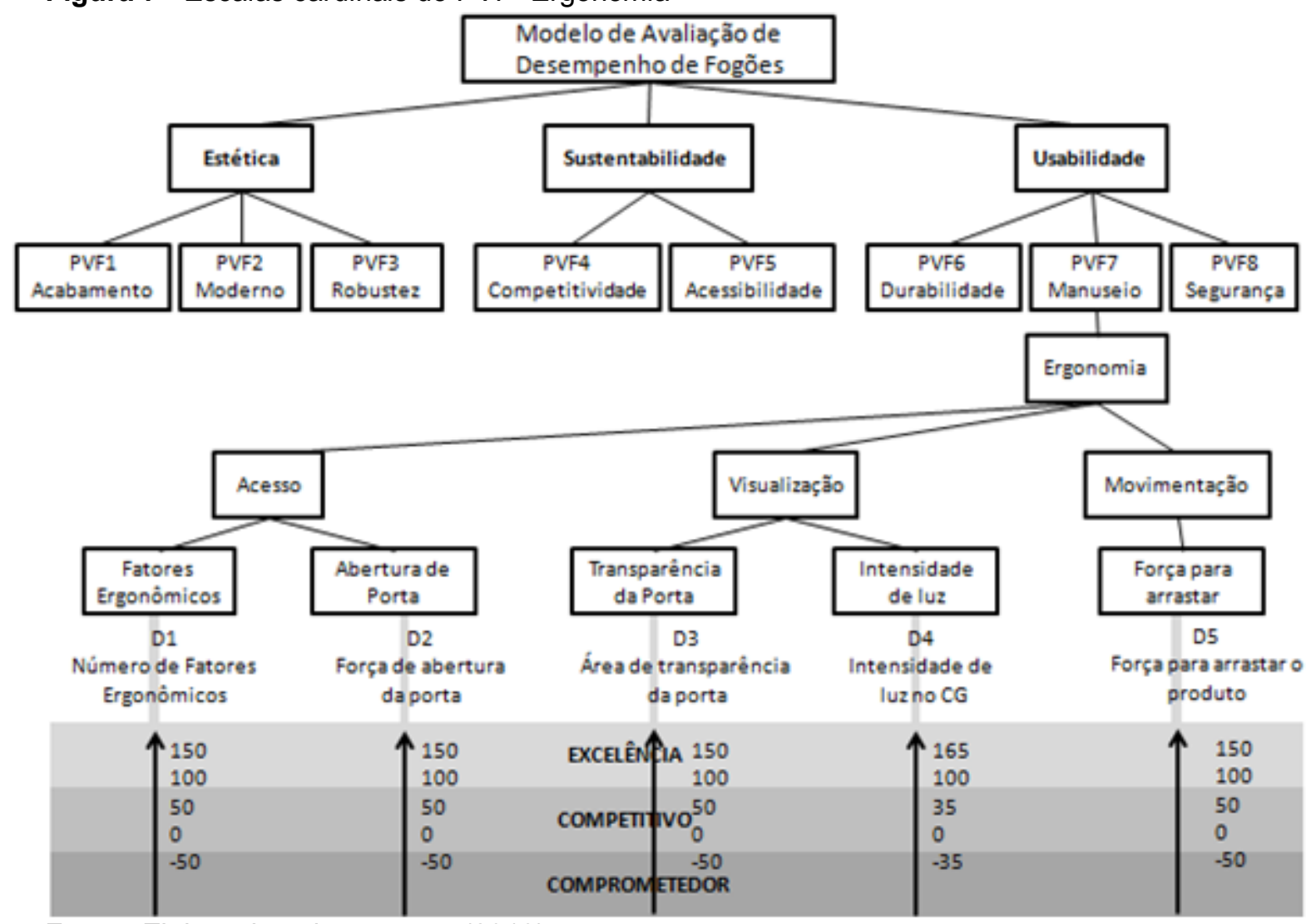

Fonte: Elaborado pelos autores (2010).

Nesta etapa do processo ter-se-á a mensuração cardinal individual de cada aspecto operacional considerado importante pelo decisor. Porém, ainda não é possível avaliar o desempenho em níveis táticos, através dos Pontos de Vista Elementares, e nem dos aspectos julgados estratégicos, através dos Pontos de Vista Fundamentais.

Para realizar esta avaliação global é necessário realizar o processo de integração de todos os pontos de vistas, segundo a percepção dos decisores, aplicando-se taxas de substituição conforme (SILVEIRA, 2007), que serão apresentadas na próxima seção. Neste trabalho todas as taxas foram definidas com a participação dos dois decisores, utilizando-se reuniões em grupos com os facilitadores para chegar a uma unificação de suas preferências (LACERDA et al., 2011).

Revista Produção Online, Florianópolis, SC, v.12, n. 2, p. 423-454, abr./jun. 2012. 


\subsubsection{Taxas de Substituição}

A Figura 8 identifica a estrutura hierárquica abaixo do PVE "Acesso", que exemplificará a integração por meio da definição das taxas (W1 e W2), que representam o juízo de valor preferencial do decisor.

Figura 8- Estrutura Hierárquica de Valor com destaque para os PVEs "Fatores Ergonômicos" e "Abertura de Porta".

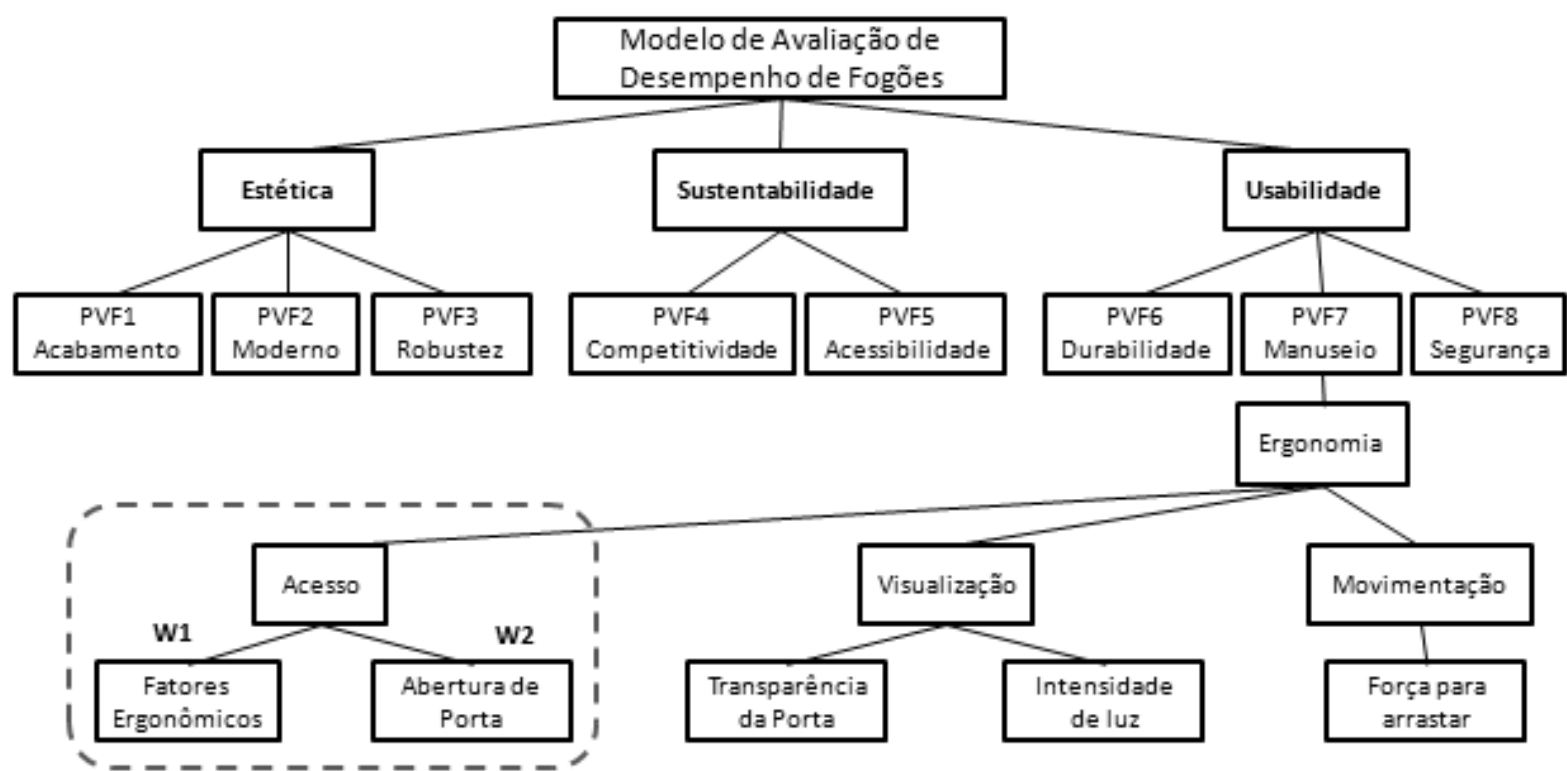

Fonte: Elaborado pelos autores (2010).

Criam-se então alternativas potenciais (A1, $A 2$, e A3) que representem a contribuição da passagem do nível "Neutro" para o nível "Bom", em cada um dos critérios que se deseja determinar as taxas, assim como uma ação de referência com desempenho "Neutro" em todos os pontos de vista, conforme apresentado na Figura 9.

Revista Produção Online, Florianópolis, SC, v.12, n. 2, p. 423-454, abr./jun. 2012. 
Figura 9 - Alternativas potenciais para determinar as taxas de substituição com a indicação dos respectivos níveis "Bom" e "Neutro"

A1

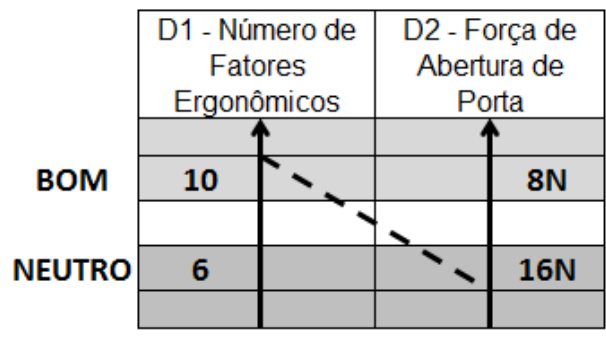

A2

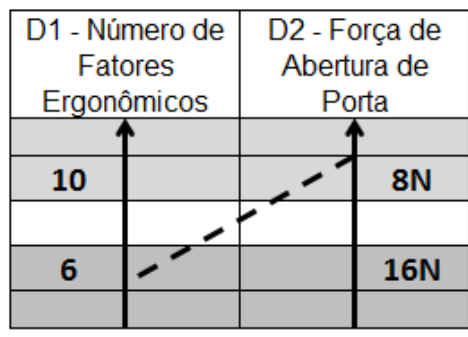

A3

\begin{tabular}{|c|c|c|c|}
\hline \multirow{2}{*}{\multicolumn{2}{|c|}{$\begin{array}{l}\text { D1 - Número de } \\
\text { Fatores } \\
\text { Ergonômicos }\end{array}$}} & \multicolumn{2}{|c|}{$\begin{array}{c}\text { D2 - Força de } \\
\text { Abertura de } \\
\text { Porta }\end{array}$} \\
\hline & & & \\
\hline 10 & & & $8 \mathrm{~N}$ \\
\hline & & & \\
\hline 6 & -- & -- & $16 \mathrm{~N}$ \\
\hline
\end{tabular}

Fonte: Elaborado pelos autores (2010).

Em seguida, realizou-se uma ordenação preferencial das alternativas, por meio de uma matriz de ordenação segundo (ROBERTS, 1979) conforme demonstrado no Quadro 4. Quando o decisor preferir a alternativa da linha, marcase na coluna com a qual está comparando o valor 1 , em caso contrário, zero. Ao final somam-se os valores das linhas e se obtém o grau de preferência conforme o valor da soma. Gera-se, desta forma, a hierarquização das alternativas, cuja ordem reflete a preferência do decisor ao passar do nível "Neutro" para o nível "Bom" em cada PVE.

Quadro 4- Matriz de Roberts da comparação das alternativas A1, A2 e A3.

\begin{tabular}{|c|c|c|c|c|c|}
\hline Acesso & A1 & A2 & A3 & SOMA & ORDEM \\
\hline A1 & & 1 & 1 & 2 & 19 \\
\hline A2 & 0 & & 1 & 1 & 29 \\
\hline A3 & 0 & 0 & & 0 & 39 \\
\hline
\end{tabular}

Fonte: Elaborado pelos autores (2010).

$\mathrm{Na}$ seqüência, utilizando a comparação par a par, através do software MACBETH, é solicitado ao decisor que julgue semanticamente a diferença de atratividade quando se troca de uma alternativa para outra, como pode ser observado na Figura 10. As categorias semânticas utilizadas são as mesmas empregadas para obter as Funções de Valor.

Figura 10- Taxas de substituição calculadas pelo MACBETH para as alternativas A1, A2 e A3.

\begin{tabular}{|c|c|c|c|c||r|}
\hline & {$[A 1]$} & {$[A 2]$} & {$[A 3]$} & [ tudo inf. ] & $\begin{array}{r}\text { Escala } \\
\text { actual }\end{array}$ \\
\hline$[A 1]$ & nula & forte & mt. forte & mt. forte & 50 \\
\hline$[A 2]$ & & nula & forte & forte & 50 \\
\hline$[A 3]$ & & & nula & nula & 0 \\
\hline
\end{tabular}

Revista Produção Online, Florianópolis, SC, v.12, n. 2, p. 423-454, abr./jun. 2012. 
Fonte: Elaborado pelos autores (2010).

Este processo é realizado para todos os PVEs da estrutura hierárquica. A Figura 11 ilustra a Estrutura Hierárquica de Valor com as Taxas de Substituição do modelo construído, para os Pontos de Vista.

De posse então das funções de valor e das taxas de substituição é possível calcular o valor da equação global de avaliação do modelo, que será vista na próxima seção.

Figura 11 - Estrutura Hierárquica de Valor com as Taxas de Substituição

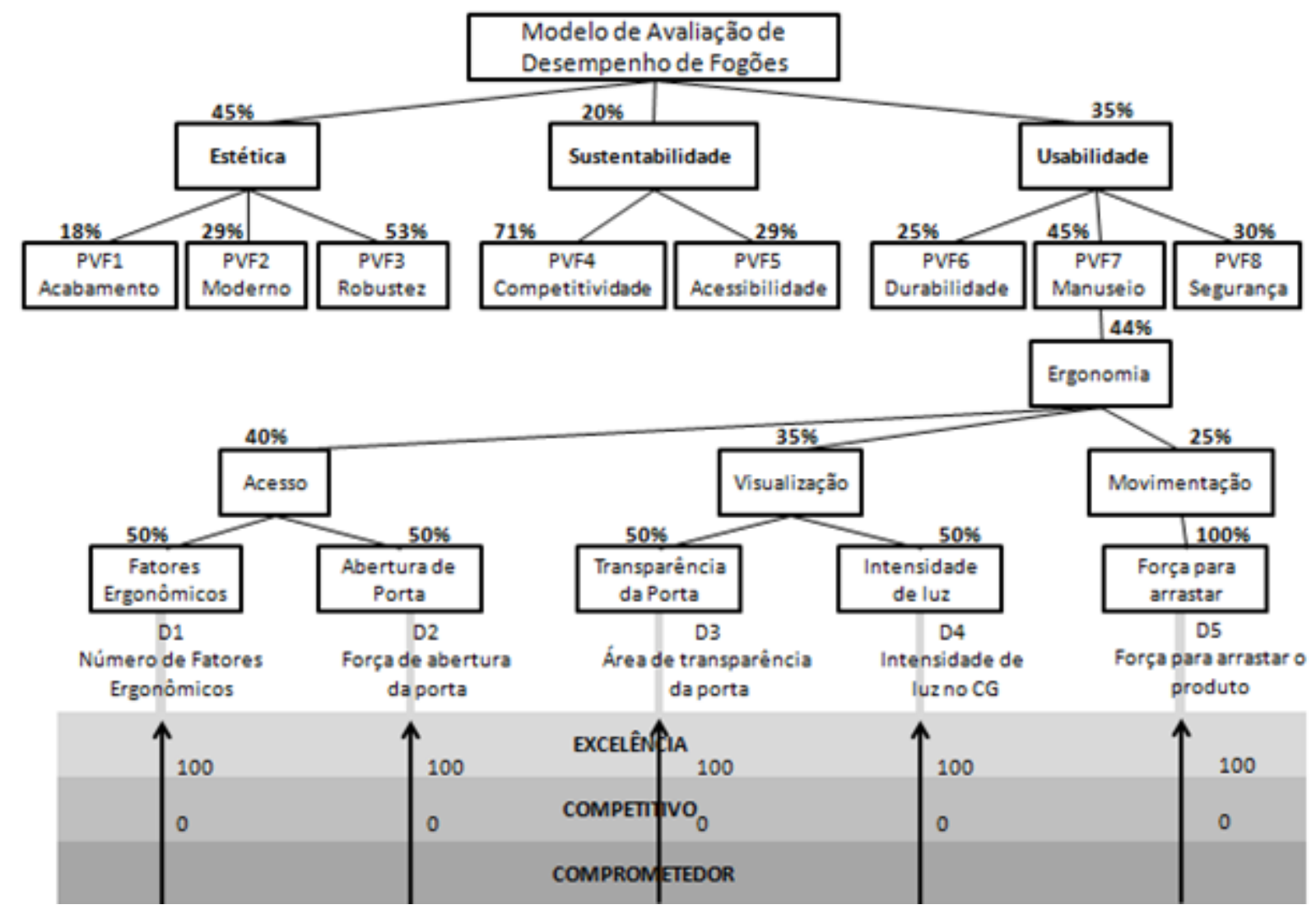

Fonte: Elaborado pelos autores (2010).

\subsubsection{Avaliação Global e Perfil de Impacto da Situação Atual}

Através da Estrutura Hierárquica de Valor construída, descritores e taxas de substituição, é possível determinar o impacto global da alternativa escolhida através do somatório dos modelos de cada PVF conforme equação 1: 
(1) $\mathbf{V}(\mathbf{a})=0,0810 \cdot \mathrm{V}_{\mathrm{PVF} 1}(\mathrm{a})+0,1015 \cdot \mathrm{V}_{\mathrm{PVF} 2}(\mathrm{a})+0,2385 . \mathrm{V}_{\mathrm{PVF} 3}(\mathrm{a})+0,1420 \cdot \mathrm{V}_{\mathrm{PVF} 4}(\mathrm{a})$ $+0,0580 \cdot V_{P V F 5}(a)+0,0875 \cdot V_{P V F G}(a)+0,1575 \cdot V_{P V F 7}(a)+0,1050 \cdot V_{P V F 8}(a)$

Onde $\mathrm{V}(\mathrm{a})$ = Pontuação global para o modelo construído;

Vale destacar que a constante que multiplica cada PVF é fruto do produto entre as taxas de substituição do PVF com sua respectiva Área de Preocupação. No caso da primeira constante "0,0810"por exemplo da equação 1 , é obtida através da multiplicação de $0,018^{*} 0,045$ (18 e 45\%) ilustrado na figura 11. Já com a equação 2 é possível calcular a pontuação de cada PVF:

(2) $V_{P V}(a)=\sum_{i=1}^{n} W_{i, k} \cdot V_{i, k}(a)$

Em que:

$V_{P V F_{\mathrm{k}}}$ : valor global da ação a do $P V F_{k}$, para $\mathrm{k}=1, \ldots \mathrm{m}$;

$v_{i, k}(a)$ : valor parcial da ação a no critério i, $\mathrm{i}=1, \ldots \mathrm{n}$, do $\mathrm{PVF}_{\mathrm{k}}$;

a: nível de impacto da ação $a$;

$w_{i, k}$ : taxas de substituição do critério $\mathrm{i}, \mathrm{i}=1, \ldots \mathrm{n}$, do $\mathrm{PVF}_{\mathrm{k}}$;

$\mathrm{n}_{\mathrm{k}}$ : número de critérios do $\mathrm{PVF}_{\mathrm{k}}$;

k: número do PVF;

Para o PVF7 ilustrado na Figura 11, ter-se-ia a equação (2):

(2) $V_{\text {PVF7 }}=0,44\left\{0,40^{*}\left(0,50^{*} V_{\text {Fatores }}(a)+0,50^{*} V_{\text {Força_Abrir }}(a)\right)+0,35^{*}\left(0,50^{*} V_{\text {Transp }}(a)\right.\right.$

$$
\left.\left.+0,50^{*} V_{\text {Intens. }}(a)\right)+0,25^{*}\left(1,00^{*} V_{\text {Força_Arrastar }}\right)\right\}
$$

Aplicando-se o mesmo principio para as Áreas de preocupação, ter-se-á a equação (3) representando o impacto no modelo global de uma ação na área de preocupação "Usabilidade":

(3) $V(a)=0,35^{\star}\left\{0,25^{*} V_{P V F 6}(a)+0,45^{*} V_{P V F 7}(a)+0,30^{*} V_{P V F 8}(a)\right\}$

Após aplicar este processo para todas as áreas de preocupação, ter-se-á o modelo global da análise multicritério para a avaliação de desempenho de fogões. 
Nesta etapa pode-se traçar o Perfil de Impacto do status quo, que permite identificar onde estão os pontos fortes de cada avaliação e em quais PVFs residem as principais oportunidades de melhoria, como ilustra a Figura 12.

Figura 12 - Perfil de Impacto do status quo de dois fogões avaliados (modelos High e Low).

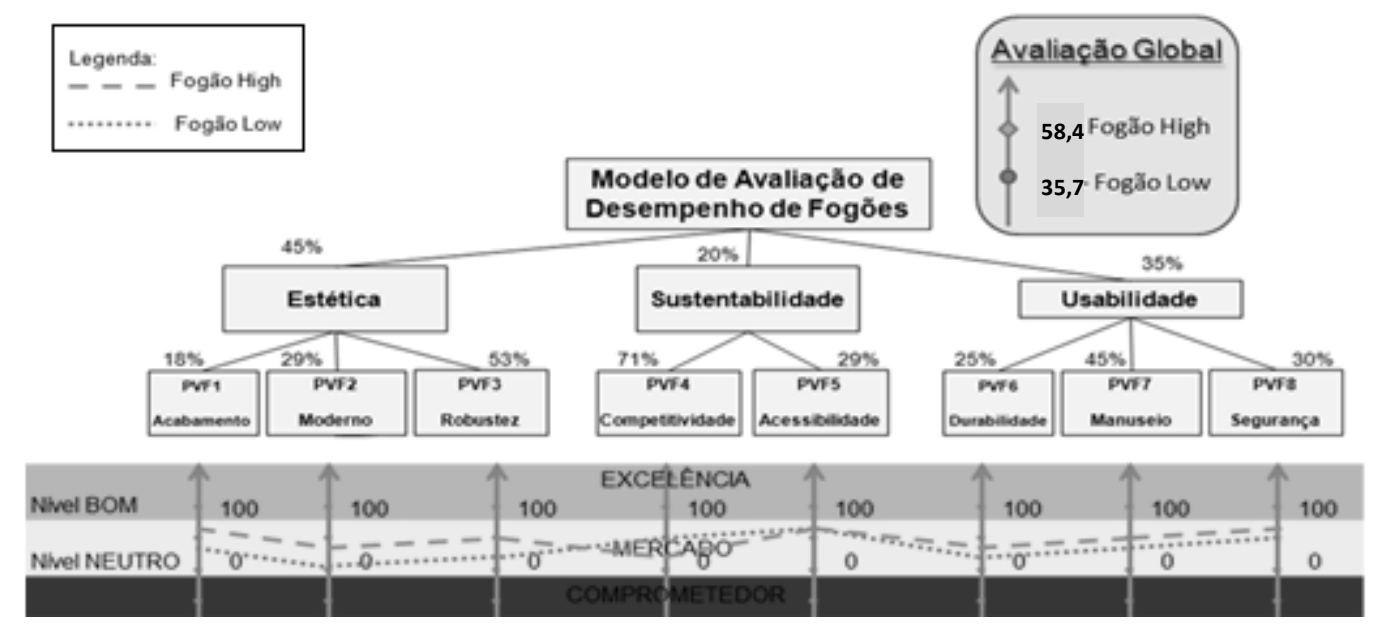

Fonte: Elaborado pelos autores (2010)

Como pode ser verificado, o perfil dos dois fogões avaliados estão alinhados com os critérios estratégicos da empresa, por não possuírem nenhum PFV em nível comprometedor. O modelo, ao ser construído segundo os valores e preferências do decisor, permitiu visualizar o desempenho comparativo entre os dois fogões. Este entendimento ajuda a identificar os locais específicos onde atuar, como o único PVF em que o Fogão High possui desempenho inferior ao Fogão Low, observado no PVF4 - Competitividade, explicado pela empresa devido ao alto custo daquele modelo. Agora, com o entendimento de onde é conveniente atuar, a empresa necessita identificar ações e avaliar o impacto das mesmas para o alcance dos objetivos estratégicos. No MCDA-C esta etapa é denominada Recomendações.

\subsubsection{Análise de Sensibilidade}

Antes de realizar a fase de recomendações, a MCDA-C recomenda a aplicação de uma Análise de Sensibilidade, que testa a resposta do desempenho 
das alternativas a variações dos seus parâmetros. Com isso, é possível também avaliar a consistência das ações de aperfeiçoamento identificadas (ENSSLIN et al., 2000).

A taxa de substituição da área de usabilidade era de $35 \%$ e foi obtida através dos julgamentos de valor do decisor no MACBETH, este por sua vez permite que a variação nos julgamentos do decisor esteja entre $33 \%$ até $38 \%$. Estas taxas não foram suficientes para inverter os resultados do Fogão High pelo Fogão low.

Esse procedimento foi realizado para as demais taxas de substituição do mesmo nível hierárquico e a análise mostrou que o modelo é robusto para qualquer uma das situações testadas, uma vez que os resultados foram consistentes.

\subsection{Fase de Recomendações}

É na etapa de aperfeiçoamento que o MCDA-C apresenta o seu diferencial perante os demais métodos uma vez que esta é capaz de identificar de forma explícita o que é importante, quantificar de forma cardinal os aspectos julgados relevantes pelo decisor e assim apresentar oportunidades de melhoria (ENSSLIN et al., 2010)

O MCDA-C é fundamentado em um processo cíclico de aperfeiçoamento que se utiliza de descritores definidos para o modelo de avaliação de desempenho com a participação do decisor que permitem estabelecer o impacto da avaliação atual (status quo) dos desempenhos locais e globais do objeto em questão e apresenta os possíveis campos de ações de melhorias e suas respectivas consequências.

O MCDA-C é construtivista e por isso é capaz de gerar conhecimento durante o processo, proporcionando assim inúmeras oportunidades de aperfeiçoamento para os modelos de fogões estudados. Deste modo, os autores recomendam uma priorização dos PVFs identificados no intuito de se obter os resultados mais eficientes e eficazes. Assim, foi estabelecido um processo composto por cinco etapas: Fórum de debate em nível estratégico para priorização, Oportunidade nos descritores, Oportunidades nos recursos existentes, Identificação das ações mais convenientes e Justificação das decisões (ENSSLIN et al., 2010). 


\subsubsection{Fórum de debate em nível estratégico para priorização}

Com um representante de cada área da empresa em nível estratégico, apresentou-se o resultado da avaliação do desempenho dos modelos de fogões low e high os quais apresentaram pontuações globais de 35,7 e 58,4 respectivamente.

Após análise dos PVFs de cada modelo assim como sua influência no desempenho global, ficou clara uma lacuna expressiva para melhorias no modelo low.

Além da constatação acima, o grupo responsável pelo planejamento e decisões estratégicas da empresa, apresentou o plano diretor no qual havia um foco no modelo low, pois o mesmo apresentava resultados financeiros negativos ao passo que o modelo high era lucrativo e ainda apresentava grande aceitação por parte dos seus consumidores.

\subsubsection{Oportunidade nos descritores}

Com base nas informações levantadas, decidiu-se focar no aperfeiçoamento do resultado global do modelo low e estabelecendo como plano de aperfeiçoamento, elevar seus descritores dos níveis atuais ao nível do modelo high devido ao fato do sucesso comprovado pelo grupo estratégico da empresa e alinhamento com o plano estratégico da empresa.

A Figura 14 representa no eixo das abscissas os descritores com seus impactos globais na avaliação de desempenho do modelo low ao passar seus descritores do nível atual ao nível do modelo high indicado no eixo das ordenadas, evidenciando a área de preocupação relacionada a cada descritor, com o objetivo de visualizar graficamente e posteriormente numericamente, a distribuição dos impactos nas áreas de preocupações Estética, Sustentabilidade e Usabilidade.

Ao consolidar os dados foi possível verificar que ao passar os descritores do modelo low ao nível do modelo high, seria possível identificar um aperfeiçoamento total de 32 pontos no impacto global do modelo de avaliação de desempenho de fogões. Desse total de pontos, ficou evidenciado no gráfico também que apenas 22 
descritores contribuem com 29 pontos, ou seja, se teria aproximadamente $25 \%$ dos descritores impactando em $90 \%$ do resultado global.

Figura 14 - Impacto no resultado global do modelo low dos 22 primeiros descritores ao passá-los do nível atual para o nível do modelo high.

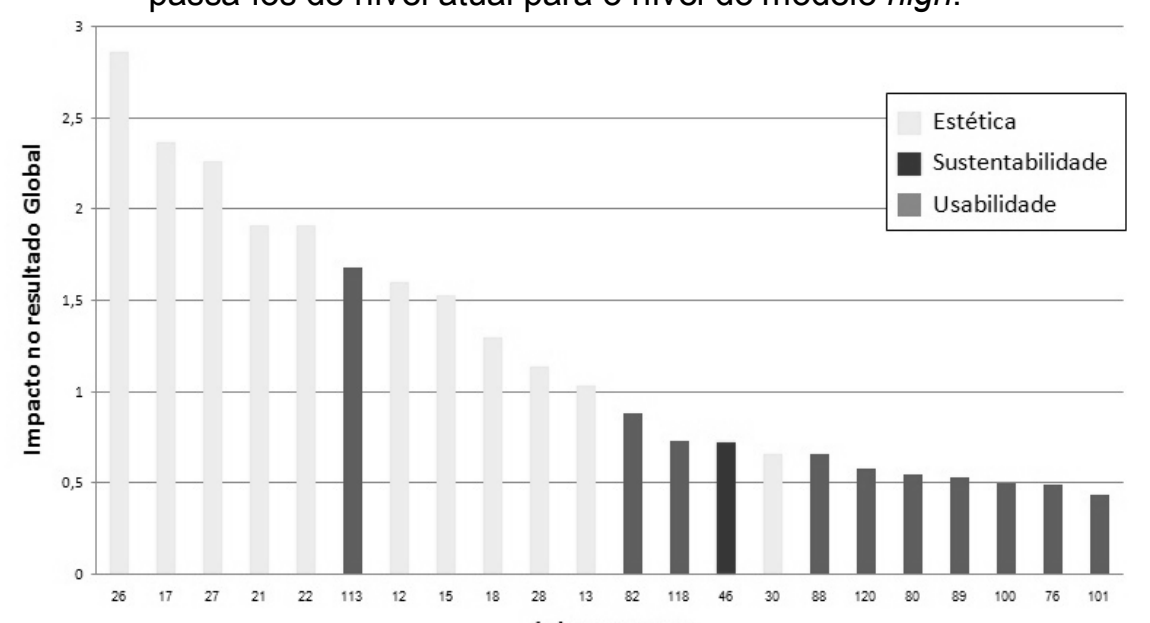

(D) Descritores

Fonte: Elaborado pelos autores (2010)

\subsubsection{Oportunidades nos recursos existentes}

$\mathrm{Na}$ etapa seguinte, resolveu-se considerar os recursos da empresa com relação às oportunidades de melhoria frente às áreas de preocupações Estética, Sustentabilidade e Usabilidade. Novamente com o grupo estratégico reunido, representantes de todas as áreas elaboraram um mapa que correlacionasse as três áreas de preocupação com o intuito de identificar todos os recursos necessários para os aperfeiçoamentos desejáveis.

Com base nesses apontamentos, o grupo verificou que a área de preocupação Estética apresentava melhor relação custo x benefício no impacto global do modelo, além do fato de estar alinhado com o planejamento estratégico da empresa.

\subsubsection{Identificação das ações mais convenientes}

O planejamento estratégico da empresa apontara para investimentos na direção do aperfeiçoamento do modelo low e ainda tendo como estratégia, passar 
seus descritores do nível atual para o nível do modelo high. Além disso, pode-se observar no modelo que poucos descritores representavam aproximadamente $90 \%$ do impacto global através da estratégia selecionada. A área de preocupação Estética contribuía com $61 \%$, seguida da área de preocupação Usabilidade $33 \%$ e por fim Sustentabilidade com 6\%.

Nos últimos anos em que a empresa do estudo de caso registrou seus investimentos e para estes avaliou o resultado de seus projetos. Ficou possível através da análise do banco de dados que as ações vinculadas à Estética tiveram melhores resultados. Podem-se destacar alguns destaques que foram extraídos dos registros: (i) investimentos com cerca de 35\% menor face as demais linhas de projetos que tinham que dispor de grande número de engenheiros, grande aporte de recursos para modificação fabril, envolvimento das áreas suporte, testes, entre outras; (ii) devido ao baixo risco em termos de funcionamento e interação com outros componentes, projetos focados em Estética tiveram um terço do tempo dos demais, o que permite colher o resultado mais cedo; e (iii) aposta dos diretores e constatação através de atividades internas na empresa mostraram também que consumidores se apaixonam pelo produto antes mesmo de tocá-los, ou seja, a primeira impressão de um produto em um grande centro expositor por exemplo é a que fica, sendo um fator que diferencia e aumentam as chances de venda do produto. Desta forma, foi evidenciada a área de preocupação Estética como a área de melhor relação custo x benefício para a empresa em questão.

\subsubsection{Justificação das decisões}

Com base no conhecimento adquirido no modelo e nas análises realizadas a partir dele, decidiu-se focar no aperfeiçoamento da área de preocupação Estética, pois a mesma representa um possível aperfeiçoamento com impacto no resultado global de 19,67 pontos e, além disso, 11 descritores dos 22 descritores que mais impactam no resultado global estavam relacionados à Estética. Com base nesta decisão traçou-se um plano de ação no qual foram relacionados os descritores de 
estética tendo como meta a passagem do seu nível atual para o nível do modelo high (metas).

Contando com o sucesso deste plano e o atendimento das metas estabelecidas espera-se que o modelo low alcance uma pontuação global 55,37 pontos, considerando sua pontuação atual de 35,7 pontos.

Por fim, com base no conhecimento adquirido através do MCDA-C, entendimento da área conveniente de atuação, identificação dos níveis atuais de desempenho com possibilidade de aperfeiçoamentos, obtenção clara dos impactos tanto locais quanto globais, o grupo de trabalho recomendou o lançamento de um novo fogão com foco das alterações estéticas (Face Lift), já tendo em mãos o plano de ação necessário para obtenção do sucesso e ainda, o valor necessário para obter cada incremento na pontuação global do modelo. Com essa fundamentação é possível ainda demonstrar para os gestores o impacto no resultado final se esses decidirem realizar algum corte no orçamento, propiciando a reflexão profunda antes de qualquer ação direcionada apenas pelo vetor custo. Assim, uma etapa que está cada vez mais comum nas empresas com as atividades de orçamentação (reduções padrão de $30 \%$ ) sem o entendimento do seu impacto tendem a diminuir, através do conhecimento gerado com todo o processo.

\section{CONSIDERAÇÕES FINAIS}

Com a utilização do MCDA-C, buscou-se desenvolver um modelo para avaliar o desempenho de fogões de uma empresa multinacional, em um contexto específico e para um grupo de atores definidos, com o objetivo de gerar um melhor entendimento do assunto e servir de subsidio ao processo de gerar ações potenciais de aperfeiçoamento pelo fato deste método possuir um processo de estruturação dos critérios identificados como relevantes pelo decisor. Dessa forma, esse artigo tem como seu objetivo geral propor um modelo de avaliação de desempenho de fogões que possibilite identificar, mensurar e integrar as dimensões julgadas pelo decisor como necessárias e suficientes no produto. Este modelo foi legitimado pelo decisor em cada etapa de sua construção e com sua utilização, o decisor e a

Revista Produção Online, Florianópolis, SC, v.12, n. 2, p. 423-454, abr./jun. 2012. 
empresa fabricante dos fogões passaram a contar com um instrumento que oportuniza a melhoria contínua dos produtos, aberto a ações de aperfeiçoamento de formas inovadoras e mais assertivas.

Como limitação da presente pesquisa, pode-se citar que o método proposto (MCDA-C) requer a participação do decisor em todo o processo. Isto decorre em consequência do foco do processo de trabalho estar centrado no desenvolvimento do entendimento do decisor. Em muitos casos o decisor poderá não ter esta disponibilidade. Outro ponto a se ressaltar é o caráter de personalização do estudo, não recomendando a aplicação do modelo em outros contextos, uma vez que o modelo foi construído segundo os valores e preferências de um decisor específico.

Como sugestão para trabalhos futuros seria interessante construir um modelo voltado para o consumidor final, dessa forma as necessidades do mesmo poderão ser mapeadas e esse material pode ajudar a empresa a melhorar seus produtos.

\section{REFERÊNCIAS}

BACK, F. T.; ENSSLIN, L. e ENSSLIN, S. R. Processo para construir o conhecimento inicial de pesquisa ilustrado ao tema gestão de recursos humanos. Revista Pesquisa \& Desenvolvimento em Engenharia de Produção. 2012 No Prelo.

BANA E COSTA, C. A. Três convicções fundamentais na prática do apoio à decisão. Pesquisa Operacional, v. 13, n. 1, p. 9-20, 1993.

BANA E COSTA, C. A. e ENSSLIN, L. Decision support systems in action: integrated application in a multicriteria decision aid process. European Journal of Operational Research, v. 113, n. 2, p. 315-335, 1999.

BANA E COSTA, C. A. e VANSNICK, J. C. Applications of the MACBETH approach in the framework of an additive aggregation model. Journal of Multi Criteria Decision Analysis, v. 6, n. 2, p. 107-114, 1997.

BANA E COSTA, C. A. B. e VANSNICK, J. C. A theoretical framework for measuring attractiveness by a categorical based evaluation technique (MACBETH). 2005. p.1524.

BETIOL, A. H. Avaliação de usabilidade para os computadores de mão: um estudo comparativo entre três abordagens para ensaios de interação. Tese 
(Doutorado em Engenharia de Produção)- Universidade Federal de Santa Catarina, 2004.

BORTOLLUZZI, S. C. Avaliação de desempenho econômico-financeiro da empresa Marel Indústria de Móveis SA: a contribuição da metodologia multicritério de apoio à decisão construtivista (MCDA-C). 2009. Dissertação (Mestrado em Contabilidade)- Universidade Federal de Santa Catarina, 2009.

BORTOLUZZI, S. C. et al. Proposta de um modelo multicritério de avaliação de desempenho econômico-financeiro para apoiar decisões de investimentos em empresas de capital aberto. CAP-Accounting and Management, v. 3, n. 3, p. 92100, 2010.

BRUNSWIK, E.; HAMMOND, K. R. e STEWART, T. R. The essential brunswik: beginnings, explications, applications. Oxford University Press, USA, 2001.

CLARK, K. B. e FUJIMOTO, T. Product development performance: strategy, organization, and management in the world auto industry. Harvard Business Press, 1991.

DIENSTMANN, J. S. et al. Gestão da Inovação e avaliação de desempenho: processo estruturado de revisão da literatura. Revista Produção Online, No Prelo.

EDEN, C.; JONES, S. e SIMS, D. Messing about in problems: an informal structured approach to their identification and management. Pergamon Press (Oxford Oxfordshire and New York), 1983.

ENSSLIN, L.; DUTRA, A. e ENSSLIN, S. R. MCDA: a constructivist approach to the management of human resources at a governmental agency. International Transactions in Operational Research, v. 7, n. 1, p. 79-100, 2000.

ENSSLIN, L. et al. Avaliação do desempenho de empresas terceirizadas com o uso da metodologia multicritério de apoio à decisão-construtivista. Pesquisa Operacional, v. 30, n. 1, p. 125-152, 2010.

ENSSLIN, L.; LONGARAY, A. A. e MACKNESS, J. R. Decision support system to aid a patient with stress to identify opportunities to improve her quality of life.

Proceedings of the Annual International Scientific Conference Operations Research, 7-9., 2005.

ENSSLIN, L.; MONTIBELLER, G. N. e NORONHA, S. M. Apoio à decisão: metodologias para estruturação de problemas e avaliação multicritério de alternativas. Florianópolis: Insular, 2001.

ENSSLIN, L. e VIANNA, W. B. O design na pesquisa quali-quantitativa em engenharia de produção-questões epistemológicas. Revista Produção Online, v. 8, n. 1, 2008. 
FONSECA, F. E. A. e ROZENFELD, H. Medição de desempenho para a gestão do ciclo de vida de produtos: uma revisão sistemática da literatura. Revista Produção Online, v. 12, 2012.

KEENEY, R. L. Value-focused thinking: a path to creative decisionmaking. Harvard Univ Pr, 1996.

KOTLER, P. Administração de marketing: a edição do novo milênio: São Paulo: Prentice Hall, 2000.

LACERDA, M. R. T.; ENSSLIN, L. e ENSSLIN, S. R. A performance measurement framework in portfolio management: a constructivist case. Management Decision, $v$. 49, n. 4, p. 9-9, 2011.

LACERDA, R. T. O.; ENSSLIN, L. e ENSSLIN, S. R. Um estudo de caso sobre gerenciamento de portfólio de projetos e apoio à decisão multicritério. Revista Gestão Industrial, v. 6, n. 1, 2010.

LANDRY, M. A note on the concept of'problem'. Organization Studies, v. 16, n. 2, p. 315, 1995.

POLETTO, Â. R.; SCHMITZ, A. L. F. e GONTIJO, L. A. Revisão de aspectos teóricos e metodológicos do uso de mapas cognitivos na ergonomia. Revista Produção Online, v. 8, n. 2, 2008.

ROBERTS, F. S. Measurement theory. Addison-Wesley, Reading, MA 1979.

ROY, B. Decision-aid and decision-making. European Journal of Operational Research, v. 45, n. 2-3, p. 324-331, 1990.

ROY, B. Decision science or decision-aid science? European Journal of Operational Research, v. 66, n. 2, p. 184-203, 1993.

ROY, B. Multicriteria methodology for decision aiding. Springer, 1996.

ROY, B. Paradigms and challenges, multiple criteria decision analysis-state of the art survey. Multicriteria Decision Analysis: state of the art survey, p. 03-24, 2005.

ROY, B. e VANDERPOOTEN, D. The European School of MCDA: emergence, basic features and current works. Journal of Multi Criteria Decision Analysis, v. 5, n. 1, p. 22-38, 1996.

SILVEIRA, C. F. Avaliação de desempenho com foco no marketing de relacionamento: um estudo de caso. Dissertação (Mestrado Programa de PósGraduação em Engenharia de Produção - PPGEP)- Universidade Federal de Santa Catarina, UFSC, Florianópolis, 2007. 
STOLT, R. e ENSSLIN, L. Avaliação de pilotos da Very Light Jets utilizando-se a MCDA-C. Conexão SIPAER, v. 1, n. 1, p. 85-103, 2009.

WHEELWRIGHT, S. C. e CLARK, K. B. Revolutionizing product development: quantum leaps in speed, efficiency, and quality. Free $\mathrm{Pr}, 1992$.

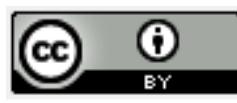

Artigo recebido em 31/12/2010 e aceito para publicação em 07/05/2012.

Revista Produção Online, Florianópolis, SC, v.12, n. 2, p. 423-454, abr./jun. 2012. 